Original Research Article

\title{
Assessment of knowledge of pharmacotherapeutics amongst medical undergraduates of a tertiary care teaching hospital of Chhattisgarh, India: a questionnaire based study
}

\author{
Ahmed Tabish ${ }^{1}$, Kaikade Swapnil ${ }^{2 *}$, Khan Tanveer A. ${ }^{1}$, Chandel N. B. ${ }^{1}$, \\ Rao Anand ${ }^{1}$, Mishra Chandresh ${ }^{1}$
}

\begin{abstract}
${ }^{1}$ Department of Pharmacology, Government Medical College, Rajnandgaon, Chhattisgarh, India

${ }^{2}$ Department of Pharmacology, Terna Medical College, Navi Mumbai, Maharashtra, India
\end{abstract}

Received: 28 September 2018 Accepted: 26 October 2018

\section{*Correspondence to: \\ Dr. Kaikade Swapnil, \\ Email:skaikade@ \\ rediffmail.com}

Copyright: () the author(s), publisher and licensee Medip Academy. This is an openaccess article distributed under the terms of the Creative Commons Attribution NonCommercial License, which permits unrestricted noncommercial use, distribution, and reproduction in any medium, provided the original work is properly cited.

\begin{abstract}
Background: Knowledge of pharmacology forms the basis of rational pharmacotherapy practice. Teaching the medical students about systematic application of pharmacology in patients' care forms an essential component. It facilitates the medical students to develop a methodical approach in solving patients' clinical problems.

Methods: A questionnaire-based study was conducted, at Government Medical College Rajnandgaon involving second year MBBS students. Total 100 students participated in the study.

Results: Hundred percent of the students responded that pharmacology was presently taught to them, seventy nine percent of them agreed with the fact that pharmacology was preferred to pass the MBBS, eighty eight percent of them responded that in pharmacokinetics was the least preferred topic, ninety seven of them were not aware of the essential drug list. Their suggestions regarding the change in teaching methodology was recorded.

Conclusions: This study concludes that efforts are needed to develop a curriculum that encompasses important aspects of clinical pharmacology and therapeutics along with incorporation of the useful suggestions by the undergraduate students.
\end{abstract}

Keywords: Clinical pharmacology and pharmacotherapeutics, Medical education, Prescription writing, Undergraduate medical curriculum

\section{INTRODUCTION}

Pharmacology forms one of the most important subjects in medical curriculum and can be considered as the backbone of Clinical Medicine. ${ }^{1}$ Prescribing the appropriate and rational therapy is the essential duty of doctors and hence, adequate knowledge about the drug's efficacy, safety, cost, and convenience is of utmost importance. ${ }^{2}$ Proper training in pharmacology can enhance medical students' knowledge and skill about drug prescription along with their utility in various diseases. ${ }^{3}$ Selection of the most appropriate drug, dosage and duration of treatment taking into account the specific features of a patient are a part of pharmacotherapeutics. ${ }^{4}$ An integrated knowledge of pharmacotherapeutics along with good clinical exposure is vital in the formation of a good healthcare professional. Nowadays the approach of horizontal integration of pharmacology along with microbiology, pathology as well as vertical integration with medicine and surgery is applied to have a proper understanding of the subject. All this is done with the help of didactic lectures, audio-visual aids, tutorials and computerized animal simulation 
experiments. ${ }^{5}$ This questionnaire based study was done to assess the knowledge of pharmacotherapeutics among $2^{\text {nd }}$ year MBBS undergraduates. The goal of this study was to investigate differences in pharmacology and pharmacotherapy knowledge of $2^{\text {nd }}$ year medical students. It can help to enhance the knowledge of pharmacotherapeutics. Knowledge of potential differences can be used to develop integrated educational programmes, both undergraduate and postgraduate, with a view to improving interdepartmental collaboration and medical care.

\section{METHODS}

A cross-sectional questionnaire-based study was conducted amongst $2^{\text {nd }}$ professional MBBS at Government Medical College Rajnandgaon. The study was performed in first week of August 2018. An exhaustive questionnaire of multiple-choice questions related to common medical conditions was prepared. Questionnaires of similar studies were taken into consideration while framing questions for the current study.$^{6-8}$ Each question had four options out of which one was correct. Test questions were discussed and reviewed by senior faculty members of the department of pharmacology. Questions that were found to be inappropriate were either removed or altered. One mark was awarded for each correct response. Based on the number of correct responses, students were given marks. Total 30 minutes were given to solve the questionnaire.

\section{Inclusion criteria}

- Second MBBS students presently studying and Exam going

- Both boys and girls

\section{Exclusion criteria}

- Referred students

- Detained students

\section{Methodology}

- Students were instructed to be meticulously solve the questionnaire

- Do not keep any question unattempt

- Give your true opinions

- Avoid discussions, cross talk

- Return the questionnaire promptly.

The data was entered in the excel sheet and was analysed and percentages were drawn accordingly.

\section{RESULTS}

Pharmacology is one of the subjects taught to second year MBBS students that is well shown by the response they gave to the question that when did you study pharmacology, all of them said presently studying (100\%).

Table 1: Knowledge of second MBBS students regarding pharmacology.

\begin{tabular}{|lll|}
\hline Questions & Answers & Percentage \\
\hline When did you study Pharmacology? & Presently studying & $100 \%$ \\
\hline Why do you study Pharmacology? & Because to be able to treat patients & $83 \%$ \\
\hline What do you prefer to study? & Everything necessary to get MBBS & $79 \%$ \\
\hline What do you want to know? & Different drugs in a group & $68 \%$ \\
\hline What do you like best? & Mechanism of action & $35 \%$ \\
\hline Which one do you like least? & Pharmacokinetics & $88 \%$ \\
\hline Which topics are you interested? & Pharmacotherapy & $47 \%$ \\
\hline
\end{tabular}

Table 2: Knowledge of students about prescribing.

\begin{tabular}{|lll|}
\hline Questions & Answers & Percentage \\
\hline Are you being taught prescription writing? & Yes & $100 \%$ \\
\hline How do you rate your prescribing knowledge? & Average & $58 \%$ \\
\hline Do you think that your knowledge has prepared you to prescribe safely? & Yes & $84 \%$ \\
\hline Do you think your knowledge has prepared you to prescribe rationally? & Yes & $93 \%$ \\
\hline Are you aware of essential drugs list? & No & $97 \%$ \\
\hline Do you know how to prescribe according to essential lists? & No & $68 \%$ \\
\hline Whether one should prescribe a newly promoted drug? & No & $76 \%$ \\
\hline Whether one should check information about drugs before prescribing & Yes & $92 \%$ \\
\hline & $\begin{array}{l}\text { Drug information through } \\
\text { If, yes which materials would you like to refer }\end{array}$ & \multirow{2}{*}{ CIMS/MIMS/Drug today/ } \\
& ADR & \\
\hline
\end{tabular}


Second MBBS forms a bridge between paraclinical and clinical exposures as an efficient knowledge of pharmacology and therapeutics will help the students later on in their succeeding years. Therefore, their knowledge of knowledge of pharmacology was assessed by the answers given to the following questions (Table 1).

As per the responses given by the students, they expressed a few inabilities due to the following reasons:

- Inadequate knowledge of the brand names of drugs to be prescribed. As the teaching mostly revolves around generic names, the students felt at a loss when required to write brand names.

- Inadequate knowledge of fixed dose combinations rational or irrational.

- Lack of knowledge of newer drugs.

- In undergraduate teaching, the main focus is on passing MBBS rather than clinical approach.

- No experience of writing prescriptions in a clinical setting.

After assessing the following questions, the students gave certain vital suggestions to improve undergraduate teaching so as to facilitate in better prescribing:

- Teaching should be more practical, with an emphasis on clinical approach.

- Pharmacology should be taught in a manner which is knowledge oriented rather than exam oriented.

- Emphasis should be made on prescription writing.

- Problem based learning should be implemented.

- Treatment of common ailments should have focused upon rather than rare ailments.

- More clinical visits should be arranged to improve bedside teaching.

\section{DISCUSSION}

The subject of pharmacology is a broad one and embraces the knowledge of the source, physical and chemical properties, compounding, physiological actions, absorption, fate along with excretion and therapeutic uses of drugs. ${ }^{9}$

Pharmacology is one of the most important subjects for training students pursuing MBBS. It forms the backbone of medical practice. Apart from providing the therapeutic uses of drugs, it also provides a deep insight into their pharmacokinetic and pharmacodynamic parameters. ${ }^{10}$

The methodical application of pharmacology knowledge and skill by medical students is important for the upcoming work as clinicians. Facilitating the medical students to develop a disciplined approach towards drug prescribing enables them for rational prescription. Prescription writing is a vital part in patient care and also can have medicolegal repercussion. The importance of writing proper prescription should be emphasized during the medical course to inculcate appropriate prescribing skill.

In present study it was found out that most students just focus on learning the pharmacology for passing MBBS rather than gaining complete knowledge of the subject. They are more concerned with the theoretical aspects like mechanism of action, pharmacokinetics seems to be the difficult arena in pharmacology.

They are eager to learn drug lists. Prescription writing is an essential part of practical pharmacology, but they don't presently understand its importance as they don't frequently and independently deal with patients. Concept of essential drug is not known to them as well as they are not well versed with the updated list. In the pharmaceutical industry emerging drugs are everyday story but there are various problems with recently marketed drugs as their efficacy is not known. Student's reliability is more on tried and tested drugs which are efficiently prescribed since a lot of time.

In this study, the majority of students checked drug information before prescribing. The most preferred source was drug indexes, followed by books, journals, the Internet, and product inserts, while very few relied on information provided by medical representatives. There are many websites that provide information about the safe and effective use of drugs, over-the-counter medications, herbal medicines, brand names and generic names of drugs, drug interactions, and treatment options. ${ }^{11}$ Subscription sources include Medical Letter, the Drug and Therapeutic Bulletin, and the Australian Prescriber. ${ }^{12}$

The essential drugs List is the foundation for every public health program aimed at reducing morbidity and mortality. It is the key strategy in helping to improve access to essential drugs and contributing to public health. Irregular access to essential medicines is an important issue in developing countries. The main causes are lack of availability, expensive drugs, no facilities or trained professionals to prescribe the drugs, inefficient pharmaceutical policies and management systems, poor funding, and bad distribution and use. ${ }^{13}$

Nowadays medical profession has become intensely competitive and globalized. It is important that the graduates and post graduates from medical institutions are well equipped with adequate knowledge and clinical skills to face challenges anywhere in the world. For this, medical institutes need to bring about innovations in medical teaching and regularly monitor them through regulatory bodies. $^{14}$ The World federation for Medical Education (WFME) has decided to form a policy to improve health system performance by promoting high quality medical education. ${ }^{15}$ Its mission is to improve the quality of higher education by establishing accreditation standards for basic medical education, post graduate medical education and continuing professional development of medical doctors. ${ }^{16-18}$ The present study is providing us valuable 
information about the knowledge of pharmacotherapeutics among Second MBBS students in a Government medical college. In other similar studies, comparison between two batches as well as between topics taught with integrated learning program versus traditional method showed that students performed better in the topics, taught with integrated approach. ${ }^{19}$

\section{CONCLUSION}

The traditional teaching is in the form of didactic lectures and bench work practicals. This form of teaching polishes the theoretical aspect of the subject but as per our study the students face difficulties in applying this knowledge towards clinical prescribing. These results give us an inspiration to improve undergraduate teaching by incorporating the essential drug lists, acquainting them with the concept of $\mathrm{P}$ drug. More emphasis could be laid on prescription writing and problem-based learning to make the students competent enough in clinical practice.

Participated present undergraduates will be the future clinicians serving the society, so it is the dire necessity of the hour to a develop a rational curriculum based on the above learning objectives which will increase the desired level of pharmacotherapeutic competence amongst our medical students.

Funding: No funding sources

Conflict of interest: None declared

Ethical approval: The study was approved by the Institutional Ethics Committee

\section{REFERENCES}

1. Chaurasia RC. Pharmacology exercise for undergraduate: MLNMC model. Int J Basic Clin Pharmacol. 2017 Jan 31;2(4):495-7.

2. Mohan L, Chogtu B, Adiga S, Shenoy S, Bairy KL, Kishore A. Undergraduate medical students' perceptions regarding personal drug selection exercise. Int $\mathrm{J}$ Pharmacol Clin Sci. 2012;1(2):61-7.

3. Upadhyaya P, Seth V, Sharma M, Ahmed M, Moghe VV, Khan ZY, et al. Prescribing knowledge in the light of undergraduate clinical pharmacology and therapeutics teaching in India: views of first-year postgraduate students. Adv Med Education Practice. 2012;3:47.

4. Tripathi KD. Introduction, routes of administration. In:Essentials of Medical Pharmacology. 7th ed. New Delhi: Jaypee Brothers Medical Publisher; 2014:2.

5. Ahmed MW, Dass P, Gulabani M, Ahmed R, Javedar P, Mishra R. undergraduate MBBS and BDS students' opinion based survey on current teaching practices in pharmacology and changes recommended for betterment of the same. J of Evolution of Med Dent Sci. 2014 Dec $15 ; 3(70)$.

6. Medical council of India regulation on graduate medical education. New Delhi: Medical Council of India; 1997.
Available at: www.entranceindia.com/.../10/GME_REGULATIONS. pdf.

7. Natu MV, Tejinder S. Objective structured practical examination (OSPE) in pharmacology-student's point of view. Indian J Pharmacol. 1994 Jul 1;26(3):188.

8. Gurumadhva RS, Sudhakara K, Vasanth K, Udupa AL, Bairy KL, Ahalya D. A scheme of practical examination in pharmacology for evaluating skills involved in problem solving. Indian J Pharmacol. 1992 Jul $1 ; 24(3): 145$

9. Rivera SM, Gilman AG. Drug invention and the pharmaceutical industry. In:The pharmacological basis of therapeutics,12th ed. New York: MCGraw-Hill Publishers;2012:3-16.

10. Khan SA, Siddiqui NI. Pharmacotherapeutics knowledge of some nonemergency and emergency conditions among medical undergraduates in an Indian medical college. Indian J Pharmacol. 2016 May;48(3):252-7.

11. DrugInfo. Drug Information Sources. Available at: http://www.

drugsrnikolov.com/drugdatabases/druginfosources.html. Accessed April 20, 2012.

12. Therapeutics Initiative. Sources of drug therapy information. Ther Lett. 2000;35:1-2. Available at: www.ti.ubc.ca > Therapeutics Letter.

13. Balasubramaniam K. Equitable pricing, affordability and access to essential drugs in developing countries: consumers perspective. In: WHO/WTO Secretariat Workshop on Differential Pricing and Financing of Essential Drugs. Available at: www. wto.org/english/tratop_e/trips_e/hosbjor_presentations_ e/35balasubramaniam_e. pdf 2001 Apr 8 .

14. Bowser D, Abbas Y, Odunleye T, Broughton E, Bossert T. Pilot study of quality of care training and knowledge in Sub-Saharan African medical schools. Int $\mathbf{J}$ Med Education. 2017;8:276.

15. WFME. Available at: http://www.wfme.org/. Accessed 2011 Dec 20.

16. WFME. Global Standards for Quality Improvement in Basic Medical Education BME in English.pdf. Available at: http://www.wfme.org/standards/bme.

17. WFME Global Standards for Quality Improvement in Postgraduate Medical Education English.pdf. Available at: http://www.wfme.org/standards/pgme.

18. WFME Global Standards for Quality Improvement in Continuing Professional Developement CPD of Medical Doctors English.pdf. Available at: http://www.wfme.org/standards/cpd.

19. Bhardwaj P, Bhardwaj N, Mahdi F, Srivastava JP, Gupta $\mathrm{U}$. Integrated teaching program using case-based learning. International Journal of Applied and Basic Medical Research. 2015 Aug;5(Suppl 1):S24-S28.

Cite this article as: Tabish A, Swapnil K, Khan TA, Chandel NB, Rao A, Chandresh M. Assessment of knowledge of pharmacotherapeutics amongst medical undergraduates of a tertiary care teaching hospital of Chhattisgarh, India: a questionnaire based study. Int J Basic Clin Pharmacol 2018;7:2405-8. 